\title{
Femur strength predictions by nonlinear homogenized voxel finite element models reflect the microarchitecture of the femoral neck
}

Citation for published version (APA):

Iori, G., Peralta, L., Reisinger, A., Heyer, F., Wyers, C., van den Bergh, J., Pahr, D., \& Raum, K. (2020). Femur strength predictions by nonlinear homogenized voxel finite element models reflect the microarchitecture of the femoral neck. Medical Engineering \& Physics, 79, 60-66.

https://doi.org/10.1016/j.medengphy.2020.03.005

Document status and date:

Published: 01/05/2020

DOI:

10.1016/j.medengphy.2020.03.005

Document Version:

Publisher's PDF, also known as Version of record

Document license:

Taverne

Please check the document version of this publication:

- A submitted manuscript is the version of the article upon submission and before peer-review. There can be important differences between the submitted version and the official published version of record.

People interested in the research are advised to contact the author for the final version of the publication, or visit the DOI to the publisher's website.

- The final author version and the galley proof are versions of the publication after peer review.

- The final published version features the final layout of the paper including the volume, issue and page numbers.

Link to publication

\footnotetext{
General rights rights.

- You may freely distribute the URL identifying the publication in the public portal. please follow below link for the End User Agreement:

www.umlib.nl/taverne-license

Take down policy

If you believe that this document breaches copyright please contact us at:

repository@maastrichtuniversity.nl

providing details and we will investigate your claim.
}

Copyright and moral rights for the publications made accessible in the public portal are retained by the authors and/or other copyright owners and it is a condition of accessing publications that users recognise and abide by the legal requirements associated with these

- Users may download and print one copy of any publication from the public portal for the purpose of private study or research.

- You may not further distribute the material or use it for any profit-making activity or commercial gain

If the publication is distributed under the terms of Article $25 \mathrm{fa}$ of the Dutch Copyright Act, indicated by the "Taverne" license above, 
Technical note

\title{
Femur strength predictions by nonlinear homogenized voxel finite element models reflect the microarchitecture of the femoral neck
}

\author{
${\text { Gianluca Iori }{ }^{\mathrm{a}} \text {, Laura Peralta }}^{\mathrm{b}, \mathrm{c}, 1}$, Andreas Reisinger ${ }^{\mathrm{d}, 1}$, Frans Heyer ${ }^{\mathrm{e}, \mathrm{f}, 1}$, Caroline Wyers ${ }^{\mathrm{e}, \mathrm{f}}$, \\ Joop van den Bergh ${ }^{\mathrm{e}, \mathrm{f}}$, Dieter Pahr ${ }^{\mathrm{d}, \mathrm{g}}$, Kay Raum ${ }^{\mathrm{a}, *}$ \\ ${ }^{a}$ Berlin-Brandenburg Center for Regenerative Therapies, Charité - Universitätsmedizin Berlin, Freie Universität Berlin, Humboldt-Universität zu Berlin, and \\ Berlin Institute of Health, Berlin, Germany \\ ${ }^{\mathrm{b}}$ Laboratoire d'Imagerie Biomédicale, Sorbonne Universités, INSERM UMR S 1146, CNRS UMR, 7371, Paris, France \\ ' Department of Biomedical Engineering, School of Biomedical Engineering E Imaging Sciences, King's College London, London, UK \\ ${ }^{\mathrm{d}}$ Division Biomechanics, Karl Landsteiner University of Health Sciences, Krems, Austria \\ e Department of Internal Medicine, NUTRIM School of Nutrition and Translational Research in Metabolism, Maastricht University Medical Center, Maastricht, \\ the Netherlands \\ ${ }^{\mathrm{f}}$ Department of Internal Medicine, VieCuri Medical Center, Venlo, the Netherlands \\ ${ }^{\mathrm{g}}$ Institute for Lightweight Design and Structural Biomechanics, TU Wien, Vienna, Austria
}

\section{A R T I C L E I N F O}

\section{Article history:}

Received 18 August 2019

Revised 10 March 2020

Accepted 17 March 2020

\section{Keywords:}

Osteoporosis

Femoral neck

Bone strength

Finite element analysis

Hip fragility

\begin{abstract}
A B S T R A C T
In the human femoral neck, the contribution of the cortical and trabecular architecture to mechanical strength is known to depend on the load direction.

In this work, we investigate if QCT-derived homogenized voxel finite element (hvFE) simulations of varying hip loading conditions can be used to study the architecture of the femoral neck. The strength of 19 pairs of human femora was measured ex vivo using nonlinear hvFE models derived from high-resolution peripheral QCT scans (voxel size: $30.3 \mu \mathrm{m}$ ). Standing and side-backwards falling loads were modeled. Quasi-static mechanical tests were performed on 20 bones for comparison. Associations of femur strength with volumetric bone mineral density (vBMD) or microstructural parameters of the femoral neck obtained from high-resolution QCT were compared between mechanical tests and simulations and between standing and falling loads.

Proximal femur strength predictions by hvFE models were positively associated with the vBMD of the femoral neck $\left(\mathrm{R}^{2}>0.61, p<0.001\right)$, as well as with its cortical thickness $\left(\mathrm{R}^{2}>0.27, p<0.001\right)$, trabecular bone volume fraction $\left(\mathrm{R}^{2}=0.42, p<0.001\right)$ and with the first two principal components of the femoral neck architecture $\left(\mathrm{R}^{2}>0.38, p<0.001\right)$. Associations between femur strength and femoral neck microarchitecture were stronger for one-legged standing than for side-backwards falling. For both loading directions, associations between structural parameters and femur strength from hvFE models were in good agreement with those from mechanical tests. This suggests that hvFE models can reflect the loaddirection-specific contribution of the femoral neck microarchitecture to femur strength.
\end{abstract}

(c) 2020 IPEM. Published by Elsevier Ltd. All rights reserved.

\section{Introduction}

Subject specific homogenized finite element (FE) models of the hip can be developed from quantitative computed tomography (QCT) datasets that are routinely available in the clinics [1] and provide femur strength predictions that are superior to those obtained from dual-energy X-ray absorptiometry (DXA, the current standard in the assessment of osteoporosis) or QCT alone [2]. The possibility to test the proximal femur in silico under multiple load-

\footnotetext{
* Corresponding author.

E-mail address: kay.raum@charite.de (K. Raum).

1 These authors contributed equally to the current work.
}

ing conditions improves the potential of FE for hip fracture prediction and represents one of the key advantages of the FE approach [3]. Simulating the mechanical solicitations of both ordinary gait and extraordinary events might identify, for example, over-adapted femora that have become particularly fragile under non-habitual loading $[4,5]$.

The fragility of the human femoral neck is determined by the amount and organization (architecture) of the bone tissue that composes it. Cortical bone thinning in the femoral neck has been associated with increased incidence of fractures [6-8]. Moreover, the trabecular bone network of the femoral neck contributes to femoral stability [9] and its architecture is altered in people with osteoporosis [10]. Furthermore, the relative importance of the cor- 


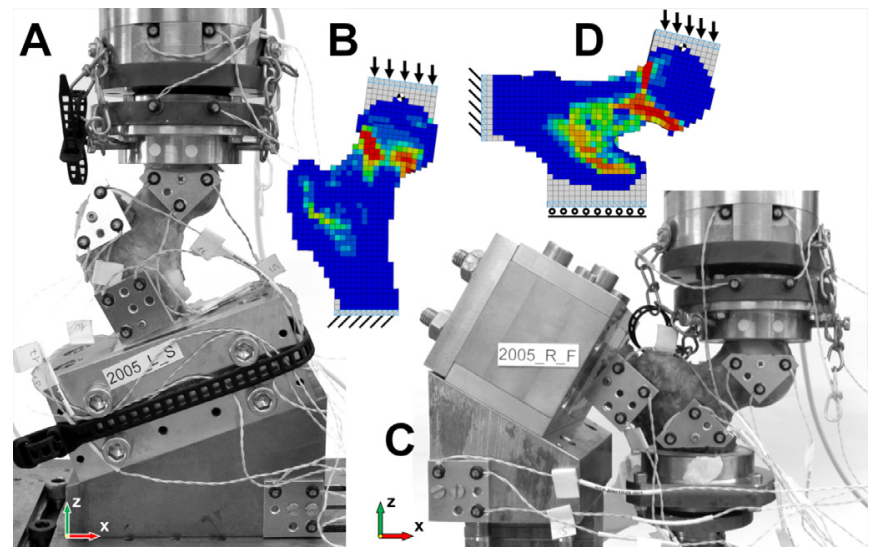

Fig. 1. Quasi-static mechanical tests and homogenized voxel FE simulations of proximal femur strength. STANCE (A and B) and FALL (C and D) measurements of proximal femur strength were conducted according to a validated protocol [14].

tical and trabecular structures in the femoral neck varies depending on the load case. During one-legged standing, hip strength has been proposed to be mainly determined by the cortical compartment, with marginal contributions from trabecular bone [11]. However, the density and connectivity of trabecular tissue have been suggested to reinforce the femoral neck particularly during a fall on the side [9].

In hvFE models of the proximal femur, cortical and trabecular tissues are homogenized to a continuum within voxels of several millimeters (Fig. 1(B) and (D)). Due to the homogenization procedure, the geometrical detail of the bone microarchitecture is lost. This raises the question if hvFE models neglect, totally or in part, the role of the bone microstructure for hip fragility.

In this study on cadaveric specimens, we assessed the degree of correlation of femur strength predictions by hvFE with the density and microstructure of femoral neck cortical and trabecular bone under both, standing and falling loading conditions. The architecture and VBMD of the femoral necks from 19 human donors were quantified on high-resolution peripheral QCT (HR-pQCT) images, whereas femur strength was measured (i) using HR-pQCT-based nonlinear hvFE models and (ii) on a subset of the bones by mechanical testing.

The goal was to elucidate if femur strength predictions by nonlinear hvFE models depend on the cortical and trabecular architectures in the femoral neck and whether this dependence varies with the direction of load.

\section{Materials and methods}

\subsection{Samples and imaging}

Left and right femora from the nineteen human donors of Table 1 were available for this research. All subjects had given consent for the scientific use of their bodies. Samples were collected at the anatomy institute of the Lübeck University in accordance with the German law. DXA scans of the proximal femora were performed on a Hologic Discovery A scanner (Discovery QDR, Hologic Inc., USA) immerging the bones in saline solution. The T-score was calculated comparing the areal BMD of the femoral neck with sexand ethnicity adjusted reference values [12].

HR-pQCT scans with isotropic voxel size of $30.3 \mu \mathrm{m}$ of the proximal femora were acquired using an XtremeCT II (Scanco Medical AG, Brüttisellen, Switzerland). The scanning procedure is described in the study by Iori and colleagues [13]. Briefly, scanner settings were: X-ray tube voltage $=68 \mathrm{kVp}$, current $=470 \mu \mathrm{A}$, integra-
Table 1

Details of the donor's age, sex and T-score. *Indicates donors selected for mechanical testing of femur strength.

\begin{tabular}{lllll}
\hline ID & Sex & Age & Condition/Medication & T-score \\
\hline \#1* & m & 88 & Pancreatic cancer & -3.00 \\
\#2 $^{*}$ & w & 80 & Lung cancer (Pancoast) & -3.63 \\
\#3* & w & 94 & (Diagnosed) osteoporosis & -4.00 \\
\#4 & w & 83 & & -2.80 \\
\#5 & m & 90 & & -3.02 \\
\#6 & w & 88 & & -3.36 \\
\#7* & m & 80 & & -3.19 \\
\#8 & w & 82 & & -2.81 \\
\#9* & w & 92 & & -3.64 \\
\#10* & m & 70 & & -1.31 \\
\#11 & w & 72 & Oral cancer/Bladder cancer & -2.35 \\
\#12* & w & 85 & & -2.32 \\
\#13 & w & 84 & & -2.52 \\
\#14* & w & 82 & & -3.30 \\
\#15* & w & 69 & Non-Hodgkin lymphoma (B-cell) & -2.44 \\
\#16 & m & 71 & & -3.21 \\
\#17 & w & 94 & & -3.93 \\
\#18 & w & 92 & Colon cancer & -3.59 \\
\#19* & m & 94 & & -4.04 \\
Median & 84.0 & & & -3.19 \\
SD & 8.4 & & & 0.69 \\
Range & 69-94 & & & $-4.04-1.31$ \\
\hline
\end{tabular}

tion time $=200 \mathrm{~ms}$, number of projections $=3000$, total rotation $=180^{\circ}$.

\subsection{Finite element modeling}

Nonlinear homogenized voxel finite element (hvFE) models were obtained from HR-pQCT images to simulate proximal femur failure under both STANCE and FALL loads (Fig. 1(B) and (D), respectively). Air voxels trapped inside the bone were set to the gray value of water and the datasets coarsened to a voxel size of $2.7 \mathrm{~mm}$. The resulting voxel intensity was converted to bone volume fraction (BV/TV) using a linear calibration rule that was obtained for the specific set of scans [13]. The constitutive law applied to the model voxels implements BV/TV-dependent elastic and damage properties and a piecewise Hill yield criterion based on stress [14]. Elasticity and yield constants for the material model were scaled according to an empirical function of the local BV/TV $[15,16]$. Each model had approximately $8 \times 10^{5}$ nodes, was generated with medtool 4.1 (Dr. Pahr Ingenieurs e.U, Pfaffstätten, Austria) and solved in Abaqus 6.12 (Simulia, Dassault Systemes, Velizy, France), requiring an average of $0.8 \mathrm{~h}$ of CPU time on a desktop workstation. The hvFE-based proximal femur strength (hvFE_Fu) in STANCE and FALL conditions was calculated as the maximum reaction force recorded during the simulations. The validation of the hvFE procedure had been previously reported [15] and was repeated for the set of samples utilized here [17].

\subsection{Mechanical testing}

The femora from the 10 randomly selected donors marked with an asterisk in Table 1 were experimentally tested to failure following an established protocol [15]. From each pair of legs, one side was tested mechanically in one-legged standing configuration (STANCE: $20^{\circ}$ inclination in the frontal plane, load direction in the plane defined by the femoral neck and shaft axes; Fig. 1(A)). The contralateral leg was tested simulating a side-backwards fall (FALL: $0^{\circ}$ internal rotation, $30^{\circ}$ adduction angle; Fig. $1(\mathrm{C})$ ). Before each test, a preconditioning cycle of 10 compressions of $2 \mathrm{~mm}$ was applied on the femoral head. After this, the femoral head was displaced at a rate of $5 \mathrm{~mm} / \mathrm{min}$ until failure, while measuring the axial force with a $100 \mathrm{kN}$ load cell (U3 force transducer, HBM, 


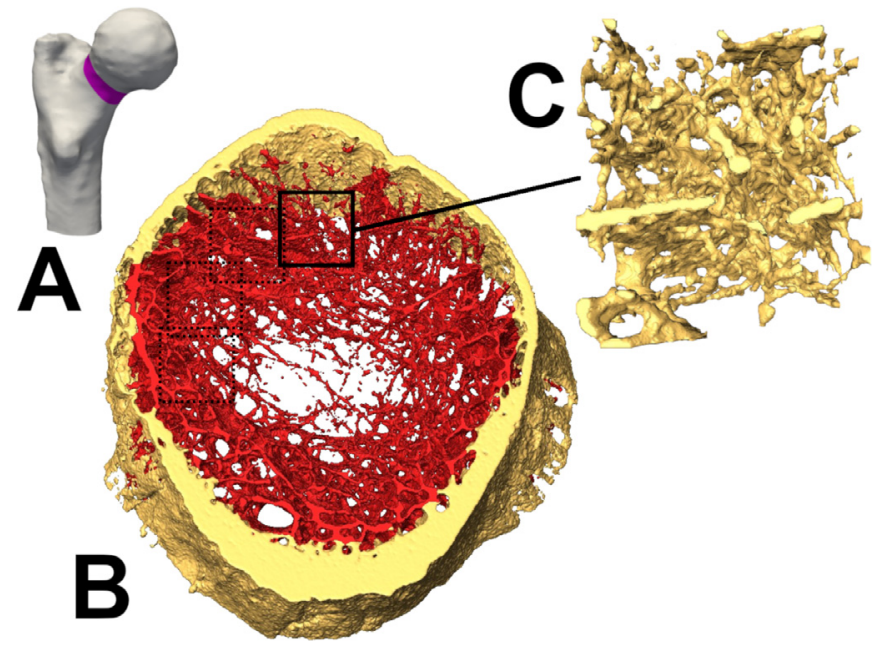

Fig. 2. 3D histomorphometry of the femoral neck. (A) Measurements were performed on a 7-mm-thick cross section of the femoral neck centered on the plane where the neck section has minimum area. (B) All images were rotated such that the image plane was perpendicular to the neck axis before separating the trabecular core (red) by a semi-automatic procedure. (C) Trabecular thickness (Tb.Th), separation (Tb.Sp) and number (Tb.N) were measured on 12 parallelepiped regions of the neck and then averaged. (For interpretation of the references to color in this figure legend, the reader is referred to the web version of this article.)

Germany). The experimental femur strength (Exp_Fu) was the ultimate force recorded during the experiment.

\subsection{Normalization of ultimate strength}

The ultimate strength of a bone depends on its size. In order to compensate for anatomical differences within the samples, femur strength was normalized dividing the ultimate force values by the minimum cross-sectional area of the femoral neck (Tt.Ar). Tt.Ar was calculated on HR-pQCT images considering both bone tissue and marrow space.

$\mathrm{Fu}_{\text {norm }}=\frac{\mathrm{Fu}}{\mathrm{Tt} \cdot \mathrm{Ar}}$

\subsection{Image processing of the femoral neck}

A 7-mm-thick cross section was extracted from the HR-pQCT images around the femoral neck section with minimum Tt.Ar (Fig. 2(A)). High-frequency noise was removed applying a 3D Gaussian filter (sigma $=1.06$ voxels). The volume was coarsened to $60.6 \mu \mathrm{m}$ voxel size and rotated aligning the z-axis with the femoral neck axis (Fig. 2(B)). Binary masks of cortical and trabecular tissues were obtained by two separate steps of adaptive thresholding [18]. The two thresholds were computed independently from the intensity histograms of only cortical and only trabecular bone, respectively. For the segmentation of the cortical compartment, an already described semi-automatic procedure [19] was adapted to the higher resolution of our data. Particularly, the endosteal boundary was manually corrected in Amira (Zuse Institute Berlin, Germany) and combined with a mask of the bone tissue as described in Supplemental Fig. 1.

\subsubsection{Density and histomorphometry calculations}

Volumetric BMD (total: vBMD, cortical: $\mathrm{vBMD}_{\text {cort }}$, and trabecular: $\mathrm{vBMD}_{\text {trab }}$ ), cortical bone porosity (Ct.Po), cortical thickness (Ct.Th) and trabecular bone volume fraction (Tb.BV/TV) of the femoral neck were measured. The percentage of cortical bone surface with Ct.Th $<0.10 \mathrm{~mm}$ (hereinafter called ultrathin) [7] and the volume ratio between trabecular and cortical bone tissue in the femoral neck [9] were also measured. Trabecular number (Tb.N), thickness (Tb.Th) and separation (Tb.Sp) were measured in medtool 4.1 (Dr. Pahr Ingenieurs e.U, Pfaffstätten, Austria) on 12 parallelepiped sub-volumes of the spongiosa distributed circumferentially around the femoral neck (Fig. 2(B) and detail in Fig. 2(C)) and then averaged.

\subsection{Statistics}

Principal component analysis (PCA) was applied to the set of microstructural variables (Ct.Po, Ct.Th, Tb.BV/TV, Tb.N, Tb.Th, Tb.Sp) to model the maximum possible variance in the microarchitecture of the femoral neck by means of two orthogonal principal components (PC1, PC2). Linear regression analysis was used to assess: (i) the correlation between pairs of structural and vBMD properties and (ii) the association of structural (including PC1 and PC2) or vBMD properties with the normalized ultimate load of the femoral neck. The latter was repeated, for the set of 10 bones tested mechanically, considering both Exp_Fu $u_{\text {norm }}$ and hvFE_Funorm. After this, the $\mathrm{R}^{2}$ with Exp_Funorm and hvFE_Fu $\mathrm{Furm}_{\text {nore }}$ were compared for each property showing significant associations with strength. Since the latter comparison relies on the accuracy of hvFE for strength prediction, Exp_Fu and hvFE_Fu were compared using paired ttests. hvFE model accuracy was characterized by the slope linear regressions with experiments and by their $\mathrm{R}^{2}$ and Standard Error of the Estimate (SEE). The significance level was set at $p<0.05$. All analyses were performed in Matlab (R2018a, The Mathworks Inc., Natick, MA, USA), unless stated otherwise.

\section{Results}

\subsection{Determinants of femur strength in the femoral neck}

The correlation among pairs of vBMD and microstructural properties of the femoral neck was up to 0.90 (vBMD $_{\text {trab }}$ and Tb.BV/TV; Table 2). Pairs of properties of the trabecular microarchitecture were also strongly correlated (Table 2). Sixty-nine percent of the total variance in the microstructure of the 38 analyzed femoral necks was explained by only two principal components (PC1 and PC2). The contribution of each microstructural variable to PC1 and PC2 is illustrated in Supplemental Fig. 2.

Plots of the linear regression between the normalized femur strength and several vBMD and microstructural properties of the femoral neck are shown in Fig. 3, for both STANCE (top) and FALL (bottom) hvFE simulations and experiments. We found significant, positive associations between hvFE_Fu $\mathrm{F}_{\text {norm }}$ and the vBMD (total and trabecular), the cortical thickness and the trabecular $\mathrm{BV} / \mathrm{TV}$ of the femoral neck (all $p<0.001$; Fig. 3). PC1 and PC2 were also strongly associated with hvFE_Fu norm $(p<0.001$; Fig. 3$)$. hvFE_Fun $\mathrm{Fu}_{\text {nom }}$ was not correlated with vBMD $\mathrm{D}_{\text {cort }}$, Ct.Po, Tb.Th, Tb.Sp or Tb.N. Linear regressions between microstructural or vBMD pa-

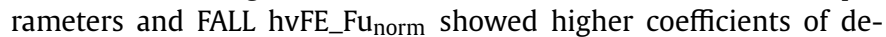
termination with generally narrower confidence intervals in comparison with regressions that considered STANCE hvFE_Funorm (Fig. 3).

\subsection{Comparison between experiments and hvFE simulations of femur strength}

Results of the comparison of proximal femur strength from mechanical tests and simulations with the hvFE method are reported in Table 3. FE models underestimated femur strength in comparison with mechanical tests ( $p<0.0001$ for both STANCE and FALL), but their precision ( $\mathrm{R}^{2}$ and SEE values in Table 3 ) was as high as in earlier hvFE validation works [15,20-22]. 
Table 2

Pairwise correlation between vBMD and microstructural properties of the femoral neck. Pooled left and right samples. $(N=38)$.

\begin{tabular}{|c|c|c|c|c|c|c|c|c|c|}
\hline \multicolumn{3}{|c|}{ Bone Mineral Density } & \multicolumn{6}{|c|}{ Bone microstructure } & \\
\hline $\mathrm{vBMD}_{\text {tot }}$ & vBMD $_{\text {cort }}$ & $\mathrm{vBMD}_{\text {trab }}$ & Ct.Th & Ct.Po & Tb.BV/TV & Tb.Th & Tb.Sp & Tb.N & \\
\hline \multirow[t]{9}{*}{1} & & $0.85^{* *}$ & $0.50^{*}$ & & $0.69^{* *}$ & $0.48^{*}$ & & & vBMD $_{\text {tot }}$ \\
\hline & 1 & & & -0.38 & & & & & vBMD ${ }_{\text {cort }}$ \\
\hline & & 1 & & & $0.90^{* *}$ & & & & vBMD ${ }_{\text {trab }}$ \\
\hline & & & 1 & & & & & & Ct.Th \\
\hline & & & & I & & 0.39 & 0.37 & & Ct.Po \\
\hline & & & & & I & & $-0.51^{*}$ & $0.65^{* *}$ & Tb.BV/TV \\
\hline & & & & & & I & $0.48^{*}$ & $-0.56^{* *}$ & Tb.Th \\
\hline & & & & & & & 1 & $-0.87^{* *}$ & Tb.Sp \\
\hline & & & & & & & & 1 & Tb.N \\
\hline
\end{tabular}
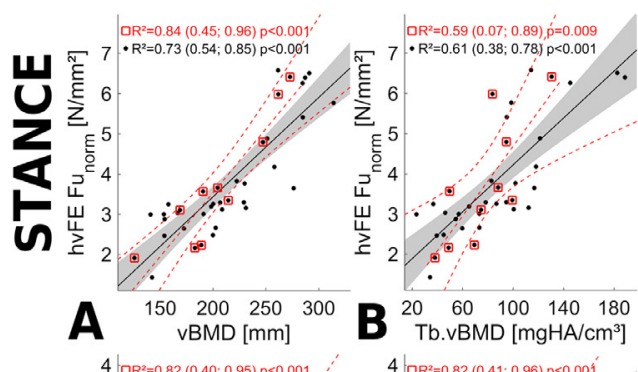

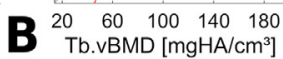
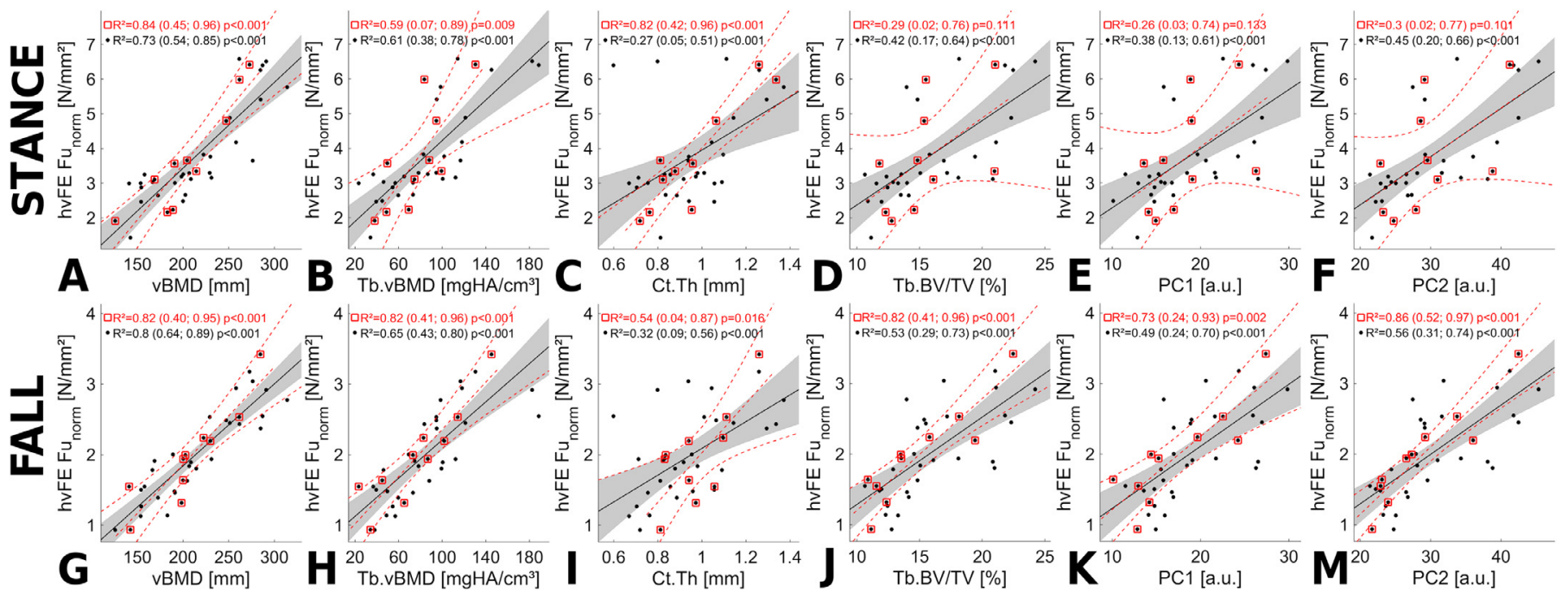

E $20 \quad 30 \quad 40$

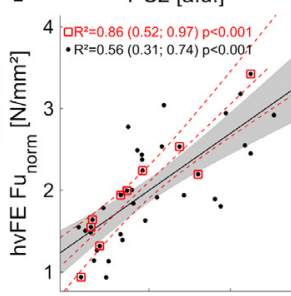

0.8
Ct.Th $[\mathrm{mm}]$

گ 20

$\mathbf{M}^{20} \stackrel{30}{30}{ }_{\mathrm{PC}[0 . u .]}^{40}$

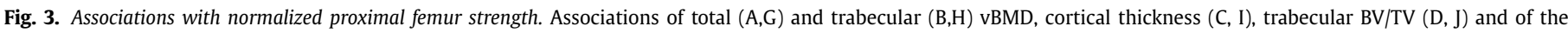

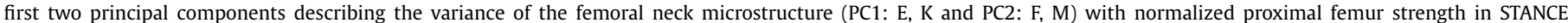

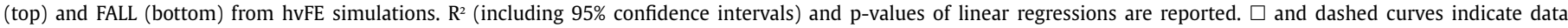

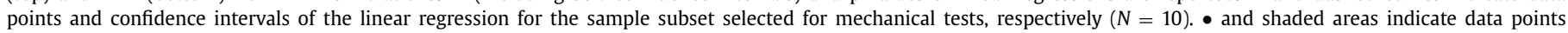

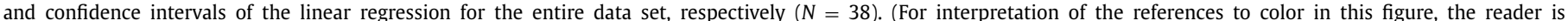
referred to the web version of this article.)

Table 3

Proximal femur strength: results from mechanical tests and hvFE simulations, coefficients of the linear regression between the two, $\mathrm{R}^{2}$ and Standard Error of the Estimate (SEE).

\begin{tabular}{lll}
\hline & STANCE $(N=10)$ & FALL $(N=10)$ \\
& Mean \pm SD $($ min-max $)$ & Mean \pm SD $($ min-max $)$ \\
\hline Exp_Fu [N] & $6646 \pm 2555(3780-12396)$ & $2292 \pm 881(1230-4026)$ \\
hvFE_Fu [N] & $2616 \pm 1117(1243-4860)$ & $1403 \pm 553(821-2691)$ \\
$\mathrm{y}=\mathrm{ax}+\mathrm{b}$ & $\mathrm{y}=2.16 \mathrm{x}+997$ & $\mathrm{y}=1.48 \mathrm{x}+213$ \\
$\mathrm{R}^{2}$ & 0.89 & 0.86 \\
SEE [N] & 800 & 309 \\
\hline
\end{tabular}

Table 4 summarizes the results (Mean $\pm \mathrm{SD}$, min, max and coefficient of variation) of structural and vBMD measurements performed at the femoral neck on the set of 20 bones tested mechanically. The last four columns of Table 4 report the coefficients of determination of the linear regressions of each architectural and vBMD variable with the ultimate load of the proximal femur after normalizing this for the whole femoral neck cross-sectional area. The coefficients are reported in separate columns for STANCE and FALL and for experiments (Exp) and hvFE simulations of proximal femur failure.

Both $v B M D$ and $\mathrm{vBMD}_{\text {trab }}$ were associated with Exp_Fu $\mathrm{u}_{\text {norm }}$ and hvFE_Funorm regardless of load configuration $\left(\mathrm{R}^{2} \geq 0.59\right.$ and $\mathrm{R}^{2} \geq 0.70$ for STANCE and FALL, respectively; all $p<0.01$; Table 4). There was no association between vBMD $_{\text {cort }}$ and femur strength (Table 4).

Ct.Th of the femoral neck was associated with the normalized ultimate load of the proximal femur for both STANCE $\left(\mathrm{R}^{2}>0.75\right.$, $p<0.01$; Table 4) and sideways FALL loads $\left(\mathrm{R}^{2}>0.54, p<0.05\right.$; Table 4). Tb.BV/TV, PC1 and PC2 were strongly associated with Exp_Fu $u_{\text {norm }}$ and hvFE_Fu $u_{\text {norm }}$ only for FALL loads $\left(\mathrm{R}^{2}>0.73\right.$, $p<0.01$; Table 4). Associations between $\mathrm{Fu}_{\text {norm }}$ and $\mathrm{Tb} . \mathrm{Th}$, Tb.Sp or Tb.N of the femoral neck were non-significant (Table 4). With the exclusion of $\mathrm{Ct}$.Th, associations between the femoral neck microstructure and Exp_Funorm or hvFE_Funorm were poor or nonsignificant for STANCE loads (Table 4). 
Table 4

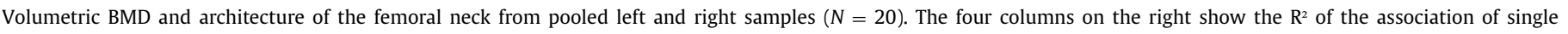

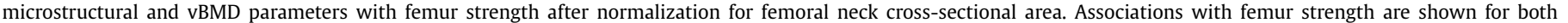
STANCE and sideways FALL loading conditions and for mechanical tests (Exp) and nonlinear homogenized voxel FE simulations (hvFE). Each group has $N=10$.

\begin{tabular}{|c|c|c|c|c|c|c|}
\hline & & & \multicolumn{4}{|l|}{$\mathrm{Fu}_{\text {norm }}$} \\
\hline & & & \multicolumn{2}{|c|}{ STANCE $(N=10)$} & \multicolumn{2}{|c|}{ FALL $(N=10)$} \\
\hline & & & Exp & hvFE & Exp & hvFE \\
\hline & Mean \pm SD (min-max $)$ & CV [\%] & \multicolumn{4}{|c|}{ Coefficient of determination $\left(\mathrm{R}^{2}\right)$} \\
\hline \multicolumn{7}{|l|}{ Volumetric Bone Mineral Density } \\
\hline $\mathrm{vBMD}\left[\mathrm{mgHA} / \mathrm{cm}^{3}\right]$ & $207 \pm 43(126-285)$ & 21 & $0.83^{* *}$ & $0.84^{* *}$ & $0.66^{*}$ & $0.82^{* *}$ \\
\hline $\mathrm{vBMD}_{\text {cort }}\left[\mathrm{mgHA} / \mathrm{cm}^{3}\right]$ & $789 \pm 48(688-885)$ & 6 & & & & \\
\hline $\mathrm{vBMD}_{\text {trab }}\left[\mathrm{mgHA} / \mathrm{cm}^{3}\right]$ & $77 \pm 31(23-145)$ & 40 & $0.64^{*}$ & $0.59^{*}$ & 0.70* & $0.82^{* *}$ \\
\hline \multicolumn{7}{|l|}{ Microstructure } \\
\hline Ct.Th $[\mathrm{mm}]$ & $0.97 \pm 0.17(0.72-1.34)$ & 18 & $0.75^{*}$ & $0.82^{* *}$ & $0.63^{*}$ & 0.54 \\
\hline Ct.Po [\%] & $3.7 \pm 1.6(1.5-7.0)$ & 44 & & & & \\
\hline Tb.BV/TV [\%] & $15.2 \pm 3.4(10.9-22.5)$ & 23 & 0.41 & & $0.87^{* *}$ & $0.82^{* *}$ \\
\hline Tb.Th $[\mathrm{mm}]$ & $0.29 \pm 0.02(0.25-0.33)$ & 9 & & & & \\
\hline Tb.Sp [mm] & $1.60 \pm 0.74(0.96-3.37)$ & 46 & & & & \\
\hline Tb.N [mm] & $0.75 \pm 0.20(0.47-1.20)$ & 27 & & & & \\
\hline PC1 & & & 0.41 & & $0.84^{* *}$ & 0.73* \\
\hline PC2 & & & 0.41 & & $0.87^{* *}$ & $0.86^{* *}$ \\
\hline \multicolumn{7}{|l|}{ Other } \\
\hline Tt.Ar $\left[\mathrm{mm}^{2}\right]$ & $7.18 \pm 1.51(5.59-10.91)$ & 21 & & & & \\
\hline Ultrathin [\%] & $13.7 \pm 8.0(3.4-33.8)$ & 59 & 0.53 & 0.57 & 0.41 & \\
\hline trabecular/cortical volume ratio & $0.75 \pm 0.20(0.47-1.20)$ & 27 & & & & \\
\hline
\end{tabular}

$\mathrm{SD}=$ standard deviation; $\mathrm{CV}=$ coefficient of variation.

Coefficients of determination reported for $p<0.05$; ${ }^{*} p<0.01 ;{ }^{*} p<0.001$.

\section{Discussion}

In this study, we examined whether nonlinear hvFE models of hip failure capture the relative contributions of femoral neck cortical and trabecular bone microarchitecture to the ultimate femur strength. Since such contributions are expected to vary depending on the load direction, we developed hvFE simulations and applied mechanical tests in two different conditions of load, i.e., physiological one-legged STANCE and side-backwards FALL. The density and microstructure of the femoral neck was analyzed on the same HRpQCT images utilized for hvFE model generation.

The slope of linear regressions between hvFE and experimental measurements of femur strength differed significantly from unity (coefficients are reported in Table 3). This is in agreement with other hvFE studies that make use of stress-based failure criteria (see Fig. 4 in [22] and Fig. 5 in [15] for comparison). The reader should note that in FE works applying strain-based failure criteria, the $\mathrm{Y}=\mathrm{X}$ agreement between model and experiment is often imposed by retrospectively scaling the elastic modulus of single finite elements. Therefore, we characterized the precision of hvFE estimates of strength by the $\mathrm{R}^{2}$ and SEE of linear regressions with experiments.

Compared with histology, HR-pQCT allowed the 3D histomorphometric characterization and precise control on the position of the femoral neck cross section selected for the analysis [23]. The measured $\mathrm{Ct}$.Th was close to values found for analogous age groups $[7,10]$. Ct.Po was lower than already reported [10], since only large pores can be segmented on HR-pQCT images [24]. Analogously, Tb.Th and Tb.BV/TV were higher than in other studies $[10,25]$ due to the physical resolution $(55.9 \mu \mathrm{m}[26])$ of 2nd generation HRpQCT. In view of the uncertain representation of thinnest trabeculae, we decided not to quantify trabecular connectivity.

Homogenized voxel FE models captured the strong association of femur strength in FALL conditions with the total and trabecular vBMD as well as with Tb.BV/TV and with the principal components describing the femoral neck microarchitecture (Fig. 3 and Table 4). Associations with femur strength were non-significant for cortical bone VBMD, cortical porosity and for several trabecular microstructural indices (thickness, separation and number) in the femoral neck. In particular the lack of association with Ct.Po can be explained by the process of age-related cortical bone resorption. This leads to the formation of large resorption units [27] which, in the femoral neck, become often connected with the marrow cavity [28]. In the femoral neck of elderly subjects this process leads to a reduction of the total cortical thickness, rather than an increase in Ct.Po [7].

Importantly, when compared on a subset of 10 samples, mechanical tests and hvFE simulations provided analogous associations between $\mathrm{Fu}_{\text {norm }}$ and the femoral neck vBMD and microstructure (Table 4). Thus, hvFE models identified the same density and structural determinants of proximal femur strength in the femoral neck as mechanical tests.

The relative contributions of femoral neck cortical and trabecular tissues to the ultimate femur strength were different depending on the direction of mechanical loading. During physiological standing, the femoral neck vBMD had the strongest association with femur strength, whereas microstructural properties were only moderately associated. Cortical thickness in particular showed strong associations with standing strength when only 10 samples from mechanical tests were considered. However, when a larger sample set was considered, the association between $\mathrm{Ct}$.Th and hvFE_Funorm was poor, likely due to the inclusion of strength outliers with low femoral neck Ct.Th (Fig. 3(C)). The poor associations between the trabecular architecture of the femoral neck and the standing strength of the proximal femur is in agreement with a previously reported experimental investigation by mechanical testing conducted ex vivo on a similar cohort of samples [11].

In the load scenario associated to the highest risk of hip fracture [29] (transversal forces of a side-backwards fall acting on the greater trochanter), trabecular BV/TV and the principal components of microstructural variance in the femoral neck showed the strongest associations with femur strength. This observation can be explained by the strengthening function accomplished by the trabecular architecture during a side-backwards fall [9], which becomes even more important for osteoporotic femora like the ones used in our study [9].

When compared on a subset of 10 bones per load condition, the strength predictions from both hvFE and mechanical test had 
very similar associations with the femoral neck vBMD and microarchitecture. In particular, both hvFE and experiments pointed to a strong association between the femoral neck trabecular architecture and femur strength during a side-backwards FALL. The agreement of simulations and experiments shown here for both STANCE and FALL is important for image modalities such as QCT and MRI [30], from which hvFE models of the proximal femur can be derived in vivo. With this respect, our results support the in-silico modeling of multiple loading conditions for the hip, since this can enhance strength [31] and fracture risk information attainable by homogenized FE models [3].

The study has three major limitations. The first one is the use of a small number of samples $(N=10)$ for the comparison between hvFE models and mechanical tests. In addition, no sample from young donors was included. The effect of the small sample size can be appreciated in the plots of Fig. 3(C) and (D), in which the linear regressions between hvFE_Fun $\mathrm{n}_{\text {norm }}$ and the femoral neck microstructural properties Ct.Th, Tb.BV/TV, PC1 and PC2 are compared for $N=38$ (black dots, gray confidence intervals) and $N=10$ (red dots and dashed confidence intervals). For Ct.Th (Fig. 3(C)), the exclusion of two bones with particularly low Ct.Th led to a much higher $\mathrm{R}^{2}$ for the $N=10$ case in comparison with the $N=38$ one. On the contrary, the reduction of sample size had a negative effect on the association between STANCE hvFE_Funorm and Tb.BV/TV (Fig. 3(D)), PC1 (Fig. 3(E)) and PC2 (Fig. 3(F)). Regression in FALL (Fig. 3(G)-(M)) was less affected by the sample number. Apart from considerations on the sample size, such hvFE validation should be confirmed on a younger cohort of donors.

Second, the mechanical testing and hvFE analyses considered only two out of the many directions of load experienced by the proximal femur during routine tasks [32] and caused by a fall to the ground [29]. Third, experiments of femur failure were based on displacement rates $(5 \mathrm{~mm} / \mathrm{min})$ lower than those experienced by the hip during gait [33] or falls [34]. The reason for measuring femur strength under quasi-static loads was to rely on a procedure already validated in terms of femur strength predictions [15]. One should remind, however, that the ultimate strength of proximal femur differs under impact and fixed displacement rate [35]. In addition, due to the viscous flow of the marrow, the strength of bulk cortical and trabecular bone tissues varies depending on the applied displacement rate [36].

\section{Conclusion}

Until now, the validation of nonlinear homogenized voxel FE models of the proximal femur has considered whole bone strength $[15,37,38]$, stiffness $[15,38]$ or fracture location [15] as output parameters for the comparison with mechanical tests. In this work, we showed that strength predictions by nonlinear hvFE obtained using different conditions of load can reflect the load-directiondependent role of the femoral neck microarchitecture. Our results support the use of hvFE to simulate varying directions of load of the human hip. Further studies should address the confirmation of our findings using clinical QCT or MRI data.

\section{Declaration of Competing Interest}

Dr. Joop van den Bergh reports grants and personal fees from Eli Lilly, Amgen and Will Pharma, outside the submitted work. All other authors have no competing interests to disclose.

\section{Acknowledgments}

This work received grants from the Deutsche Forschungsgemeinschaft (DFG Ra1380/9-1, Gl 289/8-1), from the Agence Nationale de la Recherche (ANR-14-CE35-0030-01), from the Bun- desministerium für Bildung und Forschung (BMBF, musculoskeletal research network 01EC1408L) within the subproject "characterization of cortical and subchondral bone", from the German Academic Exchange Service (DAAD, Grant no. 91578351) and from the Weijerhorst Foundation (Grant no. WH2). We thank Dr. Robert Wendlandt for the collection of samples, Dr. Emir Benca and Dr. Alexander Synek for the support during the FE analysis.

\section{Ethical approval}

The scientific use of human tissue from body donors is permitted by the German law "Gesetz über das Leichen-, Bestattungsund Friedhofswesen des Landes Schleswig-Holstein-Abschnitt II, $\S 9$ (Leichenöffnung, anatomisch)" from 04.02.2005. The donors have agreed to scientific use of their bodies.

\section{Supplementary materials}

Supplementary material associated with this article can be found, in the online version, at doi:10.1016/j.medengphy.2020.03. 005 .

\section{References}

[1] Qasim M, Farinella G, Zhang J, Li X, Yang L, Eastell R, et al. Patient-specific finite element estimated femur strength as a predictor of the risk of hip fracture: the effect of methodological determinants. Osteoporos Int 2016;27:281522. doi:10.1007/s00198-016-3597-4.

[2] Engelke K, van R B, Zysset P. FEA to measure bone strength: a review. Clinic Rev Bone Miner Metab 2016;14:26-37. doi:10.1007/s12018-015-9201-1.

[3] Falcinelli C, Schileo E, Balistreri L, Baruffaldi F, Bordini B, Viceconti M, et al. Multiple loading conditions analysis can improve the association between finite element bone strength estimates and proximal femur fractures: a preliminary study in elderly women. Bone 2014;67:71-80. doi:10.1016/j.bone.2014.06. 038.

[4] Weinans H. Is osteoporosis a matter of over-adaptation? Technol Health Care 1998:6:299-306.

[5] Verhulp E. Analyses of trabecular bone failure 2006. doi:10.6100/IR608109.

[6] Poole KES, Treece GM, Mayhew PM, Vaculík J, Dungl P, Horák M, et al. Cortical thickness mapping to identify focal osteoporosis in patients with hip fracture. PLOS One 2012;7:e38466. doi:10.1371/journal.pone.0038466.

[7] Power J, Loveridge N, Kröger H, Parker M, Reeve J. Femoral neck cortical bone in female and male hip fracture cases: differential contrasts in cortical width and sub-periosteal porosity in 112 cases and controls. Bone 2018;114:81-9. doi:10.1016/j.bone.2018.05.027.

[8] Johannesdottir F, Poole KES, Reeve J, Siggeirsdottir K, Aspelund T, Mogensen B, et al. Distribution of cortical bone in the femoral neck and hip fracture: a prospective case-control analysis of 143 incident hip fractures; the AGESREYKJAVIK study. Bone 2011;48:1268-76. doi:10.1016/j.bone.2011.03.776.

[9] Nawathe S, Akhlaghpour H, Bouxsein ML, Keaveny TM. Microstructural failure mechanisms in the human proximal femur for sideways fall loading: femoral strength micromechanics. J Bone Mineral Res 2014;29:507-15. doi:10.1002/ jbmr.2033.

[10] Blain H, Chavassieux P, Portero-Muzy N, Bonnel F, Canovas F, Chammas M, et al. Cortical and trabecular bone distribution in the femoral neck in osteoporosis and osteoarthritis. Bone 2008;43:862-8. doi:10.1016/j.bone.2008.07. 236.

[11] Holzer G, von Skrbensky G, Holzer LA, Pichl W. Hip fractures and the contribution of cortical versus trabecular bone to femoral neck strength. J Bone Mineral Res 2009;24:468-74. doi:10.1359/jbmr.081108.

[12] Looker AC, Wahner HW, Dunn WL, Calvo MS, Harris TB, Heyse SP, et al. Updated data on proximal femur bone mineral levels of US adults. Osteoporos Int 1998;8:468-90. doi:10.1007/s001980050093.

[13] Iori G, Heyer F, Kilappa V, Wyers C, Varga P, Schneider J, et al. BMD-based assessment of local porosity in human femoral cortical bone. Bone 2018;114:5061. doi:10.1016/j.bone.2018.05.028

[14] Garcia D, Zysset PK, Charlebois M, Curnier A. A three-dimensional elastic plastic damage constitutive law for bone tissue. Biomech Model Mechanobiol 2008;8:149-65. doi:10.1007/s10237-008-0125-2.

[15] Dall'Ara E, Luisier B, Schmidt R, Kainberger F, Zysset P, Pahr D. A nonlinear QCT-based finite element model validation study for the human femur tested in two configurations in vitro. Bone 2013;52:27-38. doi:10.1016/j.bone.2012.09. 006.

[16] Rincón-Kohli L, Zysset PK. Multi-axial mechanical properties of human trabecular bone. Biomech Model Mechanobiol 2008;8:195-208. doi:10.1007| s10237-008-0128-z.

[17] Iori G, Schneider J, Reisinger A, Heyer F, Peralta L, Wyers C, et al. Large cortical bone pores in the tibia are associated with proximal femur strength. PLOS One 2019;14:e0215405. doi:10.1371/journal.pone.0215405. 
[18] Ridler T, Calvard S. Picture thresholding using an iterative selection method. IEEE Trans Syst Man Cybern 1978;8:630-2.

[19] Burghardt AJ, Buie HR, Laib A, Majumdar S, Boyd SK. Reproducibility of direct quantitative measures of cortical bone microarchitecture of the distal radius and tibia by HR-pQCT. Bone 2010;47:519-28. doi:10.1016/j.bone.2010.05.034.

[20] Keyak JH. Improved prediction of proximal femoral fracture load using nonlinear finite element models. Med Eng Phys 2001;23:165-73. doi:10.1016 S1350-4533(01)00045-5.

[21] Schileo E, Balistreri L, Grassi L, Cristofolini L, Taddei F. To what extent can linear finite element models of human femora predict failure under stance and fall loading configurations? J Biomech 2014;47:3531-8. doi:10.1016/j.jbiomech. 2014.08.024.

[22] Varga P, Schwiedrzik J, Zysset PK, Fliri-Hofmann L, Widmer D, Gueorguiev B, et al. Nonlinear quasi-static finite element simulations predict in vitro strength of human proximal femora assessed in a dynamic sideways fall setup. J Mech Behav Biomed Mater 2016;57:116-27. doi:10.1016/j.jmbbm.2015.11.026.

[23] Lang T, Keyak J, Heitz M, Augat P, Lu Y, Mathur A, et al. Volumetric quantitative computed tomography of the proximal femur: precision and relation to bone strength. Bone 1997;21:101-8.

[24] Jorgenson BL, Buie HR, McErlain DD, Sandino C, Boyd SK. A comparison of methods for in vivo assessment of cortical porosity in the human appendicular skeleton. Bone 2015;73:167-75. doi:10.1016/j.bone.2014.11.023.

[25] Bell KL, Loveridge N, Power J, Garrahan N, Stanton M, Lunt M, et al. Structure of the femoral neck in hip fracture: cortical bone loss in the inferoanterior to superoposterior axis. J Bone Mineral Res 1999;14:111-19. doi:10.1359/jbmr. 1999.14.1.111.

[26] Metcalf LM, Dall'Ara E, Paggiosi MA, Rochester JR, Vilayphiou N, Kemp GJ, et al. Validation of calcaneus trabecular microstructure measurements by HR-pQCT. Bone 2018;106:69-77. doi:10.1016/j.bone.2017.09.013.

[27] Andreasen CM, Delaisse J-M, Eerden BC van der, Leeuwen JP van, Ding M, Andersen TL. Understanding age-induced cortical porosity in women: the accumulation and coalescence of eroded cavities upon existing intracortical canals is the main contributor. J Bone Mineral Res 2017;33:606-20. doi:10.1002/jbmr. 3354.

[28] Jordan GR, Loveridge N, Bell KL, Power J, Rushton N, Reeve J. Spatial clustering of remodeling osteons in the femoral neck cortex: a cause of weakness in hip fracture? Bone 2000;26:305-13. doi:10.1016/S8756-3282(99)00272-0.
[29] Keyak JH, Skinner HB, Fleming JA. Effect of force direction on femoral fracture load for two types of loading conditions. J Orthop Res 2001;19:539-44. doi:10. 1016/S0736-0266(00)00046-2.

[30] Chang G, Deniz CM, Honig S, Rajapakse CS, Egol K, Regatte RR, et al. Feasibility of three-dimensional MRI of proximal femur microarchitecture at 3 tesla using 26 receive elements without and with parallel imaging. J Magn Reson Imaging 2014;40:229-38. doi:10.1002/jmri.24345.

[31] Keyak JH. Relationships between femoral fracture loads for two load configurations. J Biomech 2000;33:499-502. doi:10.1016/S0021-9290(99)00202-X.

[32] Bergmann G, Deuretzbacher G, Heller M, Graichen F, Rohlmann A, Strauss ], et al. Hip contact forces and gait patterns from routine activities. J Biomech 2001;34:859-71. doi:10.1016/S0021-9290(01)00040-9.

[33] Grassi L, Väänänen SP, Amin Yavari S, Jurvelin JS, Weinans H, Ristinmaa $M$ et al. Full-field strain measurement during mechanical testing of the human femur at physiologically relevant strain rates. J Biomech Eng 2014;136 111010111010-8. doi:10.1115/1.4028415.

[34] de Bakker PM, Manske SL, Ebacher V, Oxland TR, Cripton PA, Guy P. During sideways falls proximal femur fractures initiate in the superolateral cortex: evidence from high-speed video of simulated fractures. J Biomech 2009;42:191725. doi:10.1016/j.jbiomech.2009.05.001

[35] Gilchrist S, Nishiyama KK, de Bakker P, Guy P, Boyd SK, Oxland T, et al. Proximal femur elastic behaviour is the same in impact and constant displacement rate fall simulation. J Biomech 2014;47:3744-9. doi:10.1016/j.jbiomech.2014.06. 040.

[36] Carter DR, Hayes WC. Bone compressive strength: the influence of density and strain rate. Science 1976;194:1174-6. doi:10.1126/science.996549.

[37] Keyak JH, Rossi SA, Jones KA, Skinner HB. Prediction of femoral fracture load using automated finite element modeling. J Biomech 1997;31:125-33.

[38] Nishiyama KK, Gilchrist S, Guy P, Cripton P, Boyd SK. Proximal femur bone strength estimated by a computationally fast finite element analysis in a sideways fall configuration. J Biomech 2013;46:1231-6. doi:10.1016/j.jbiomech. 2013.02.025. 